\title{
PENSAMIENTO LÓGICO Y PENSAMIENTO MÍTICO
}

\author{
Hernán Malo González
}


En el capítulo primero de su libro Esquemas para una historia de la Filosofía Ecuatoriana, Arturo Andrés Roig se plantea la pregunta de si cabe o no hablar de Filosofía en Ecuador. A modo de "videtur quod non" trae la autoridad de José Rafael Bustamante y de Benjamín Carrión:

.....no ha habido Filosofía en América..... En el Ecuador la cultura filosófica no existe. En el Ecuador, pueblo azotado como ninguno por las males de la raza y de la naturaleza, la carencia de filosofía es quizás más notable que en los demás.... la filosofía no es fruto de las sociedades y pueblos primitivos e incipientes....

afirma Bustamante en un artículo intitulada Filosofía, que aparece en el revista "América" el año 1935 (Quito, No. 60-61, p. 166, 177, etc.). Y Benjamín Carrión, en su artículo Historia de las Ideas en el Ecuador publicado al año 1959 en "Revista de Historia de las Ideas" (Quito, No. 1, p. 251-253), califica al Ecuador de "tierra sin filósofos".

La respuesta de Roig es del todo encontrada. Parte de la distinción muy valiosa, que hace Francisco Miró Quesada en su libro Despertar y proyecto del filosofar latinoamericano: Existen dos tendencias en nuestro quehacer filosófico. La una puede llamarse asuntiva: es la "que ejercen todos aquellos, cuya pretensión fundamental es la de instalarse en la tradición europea...." La otra se puede designar como afirmativa: "....se caracteriza por el hecho de hacer filosofía sobre la base del reconocimiento de la existencia de un pensamiento latinoamericano original, en particular si lo miramos desde el punto de vista de la circunstancia".

Ambas son necesarias. Lo es más la segunda que, por llenar el requisito de un reflexionar con intención de hondura sobre hechos trascendentales, merece el nombre de filosofía. 
Aunque tal vez al borde de una "lis de verbo", estoy de acuerdo con Roig en no estar de acuerdo con el Maestro Gaos, el cual prefiere el vocablo pensamiento al de filosofía, entendiendo aquel como eso que es y no es filosofía. Sobre el asunto, y dentro de un contexto más amplio, volveremos en el cuerpo de la disertación.

La batalla por el término es todo un signo, toda una referencia de contenidos, toda una toma de posición. Pasando de él al asunto, que late como cuestión de fondo: nuestro derecho y nuestra libertad de pensar, citemos nuevamente a Roig:

Sólo por la vía de una comprensión de la idea, como elemento determinado y determinante en relación con el sistema de conexiones de cada época, será posible alcanzar un saber propio y en tal sentido genuino, original y auténtico. Aclarando que estos buscados caracteres, no deben ser perseguidos nunca en sí mismos, sino que ellos aparecen simplemente cuando se da con la clave, que nos abre a nuestra propia realidad. El error de muchos de los intelectuales latinoamericanos consistió precisamente en proponerse como tarea la de ser diferenciables mediante la elaboración de una producción literaria original. Lo único que hay original es siempre la realidad misma y es ella la que, en la medida que somos capaces de captarla, nos hará originales. Tal es la fecunda tesis del "filosofar sin más" de Leopoldo Zea.

Dentro de esta línea (para subrayar enfáticamente su importancia), y con referencia más concreta a Ecuador, repito lo que en el prólogo al citado libro de Arturo Andrés Roig afirmé:

Mucho debe hacernos pensar la sabia y verídica acotación del filósofo argentino (sobre el puro literatismo o parcialismo sectario o despectivamente europeizante de la crítica de los ecuatorianos acerca del pensar de sus coterráneos). Es verdad que en el campo de la pura indagación histórica se han hecho estudios por demás serios por parte de estudiosos ecuatorianos..... Pero en la historia del pensamiento, de la filosofía ecuatoriana, reina o la vaciedad o la exacerbación de la postura ideológica, expresada corno el rechazo sectario de 
las ideas del adversario o como exaltación apasionada de las doctrinas del amigo: Tris- te y subdesarrollada realidad, que a la postre nos mantiene en un gran engaño (1).

Más aún, a fin de que abundemos en prenotando de tan señalada importancia, no olvidemos que el pensar no filosófico es parte sumamente rica del pensar filosófico (valga en toda su intensidad la paradoja) del Occidente helenizado. Pensemos en Heráclito, en que la gran visión metafísico gnoseológica del libro VII de la República descansa sobre una parábola al estilo evangélico. Filósofos como Nietzsche y Kierkegaard responden más al pensar que al filosofar.

Es más, Schelling entró en el sentimiento esotérico de una mística oriental, para revitalizar la filosofía germana: la décima (última) de sus "Philosophische Briefe über dogmatismus und Kritizismus" concluye así:

En adelante el sabio jamás se refugiará en los misterios, para proteger sus principios de las miradas profanas. Aquellos principios que en general son transmisibles, pero la misma naturaleza ha trazado límites a esta transmisibilidad. Ella ha reservado para quienes son dignos de una filosofía, que por sí misma se vuelve esotérica; ya que ella no puede ser ni aprendida, ni ofrecida en regalo ni memorizada.... Sino que es un símbolo de unión (para la unión) de los espíritus libres, en el que ellos reconocen todo, el cual sin embargo sólo es comprensible para ellos; para los otros en cambio será siempre un enigma eterno (ein fuiges raetsel).

Mi estudio será pues un pensar sin mayor rigorismo de escuela filosófica y se referirá en buena parte a lo que puede llamarse esotérico y que se mueve en la esfera de los símbolos.

\section{El estado de la cuestión.}

A partir de lo afirmado, podrá el tema Pensamiento lógico y Pensamiento mítico plantearse como la contraposición entre pensar filosófico y pensar "primitivo" (no filosófico). El común de Latinoamérica, como de otros pueblos, que fueron o que son, entraría en esta forma de cultura: 
Martín Heidegger es categórico en este punto:

LA AFIRMACION: la filosofía es en su esencia griega, dice en el estudio "Was ist das die Philosophie", que significa nada menos que lo siguiente: Que el occidente y Europa, y solamente ellos, son originariamente en su más íntimo proceso histórico filosóficos. Esto se atestigua con el surgimiento y dominio de las ciencias. Porque ellas proceden y se arraigan en lo más radical del proceso histórico de occidente europeo, es a saber en el proceso filosófico, por eso ellas (las ciencias) han sido capaces de imponer el sello específico a la historia de los hombres sobre la tierra en la actualidad. Reflexionemos un momento lo que significa el que se caracterice una era de la historia de la humanidad como la era "atómica": Ia energía atómica, descubierta y desatada mediante las ciencias. Se señala como el poder destinado a determinar el curso de la Historia. Y ciertísimamente no habría habido ciencias, si no hubiese habido (como antecedente y guía) la filosofía. Ahora también la filosofía es he philosopia (2).

Huelgan los comentarios. De acuerdo a él, la Filosofía, las Ciencias, la tónica actual del mundo, son producto casi exclusivo de Europa.

En este punto puede abrirse una controversia tan vasta y radical como la pregunta misma sobre qué es cultura. Se puede con justicia preguntar quién tiene el derecho a imponer un contenido determinado a vocablos como filosofía, ciencia, etc. Planteada tan así la cuestión, posiblemente no quedaría otro argumento en favor de Heidegger que el que concede el origen helénico de la palabra.

Por cierto, digámoslo de paso, que el primero en acudir al término fue Heráclito: en el fragmento 35 (de acuerdo a la copilación de Hermann Diels) nos dice:

Los filósofos deben estar informados de muchas cosas. 
Ahora bien, da la coincidencia de que Heráclito (tal como veremos más adelante) fue un filósofo muy poco "filosófico" y muy de contextura "mítica".

No vamos a entrar en la polémica. Apuntemos tan sólo que, aún entre los propios germanos, no existe armonía de términos. Así Hegel (nada menos que Hegel) no sólo niega derechos de filosofía a la cultura india, aduciendo como razón su identidad, en cuanto "filosofía" (sabiduría....), con la religión hindú; sino que ni siquiera le reconoce el título de pensamiento (das Gendake, das Denken). Aunque admite allí la presencia de nociones filosóficas, sostiene que éstas no pueden adoptar la forma de pensamiento, sino que están moldeadas en formas poéticas y simbólicas y tienen, como la religión, la finalidad práctica de liberar al hombre de las ilusiones y desventuras de la vida, más bien que alcanzar el conocimiento por sí mismo (3).

Luego nos tocará acordar (si se quiere provisionalmente) la terminología. Por el momento aceptemos (mal quizás de nuestro grado) lo que tiene de verdad contundente la visión de Hegel y la sentencia de Heidegger: existe una Filosofía, aceptada de alguna manera por nosotros mismos como la antonomástica, que es prerrogativa de la esfera grecoeuropea. Más adelante señalaremos sus rasgos. Esta filosofía ha tenido influjo preponderante en la evolución cultural nuestra y del mundo en general. Su derivado primordial han sido las Ciencias, entendidas como el conocimiento de alguna manera basado en la experiencia sensible, reflejamente comprobado, sistemáticamente ordenado y proyectado hacia la técnica.

En lo que hace a nuestro tema, recordemos que nuestros destacados hombres de ciencia han tenido muy presente este concepto restrictivo de lo científico, para aplicarlo aun a temas tan imponderables al parecer, como la religión:

En su libro La religión del Imperio de los Incas, publicado el año 1919, dice Jacinto Jijón, a modo de compendio y alcance de la obra:

Consideramos en esta obra la religión como un fenómeno social, propio a la naturaleza del hombre, y lo estudiamos con criterio antropológico. Cada fenómeno religioso lo analizamos comparativamente con los fenómenos semejantes, que se observan en otros pueblos de nuestro Continente y del Viejo Mundo; así el estudio de la religión incaica es también 
el de los fenómenos religiosos, que en ella ocurren. Al hacer las comparaciones, no pretendemos establecer relación genética entre unos ejemplos y otros: simples coincidencias de la naturaleza humana, u obra de contacto y propagación cultural, sólo nos interesan en cuanto nos dan a conocer la esencia del hecho religioso, que investigamos (4).

He ahí una muy respetable actitud científica de cuño netamente greco-occidental referida a algo muy íntimo de nuestro ser indoamericano: Se trata de indagar la ESENCIA de un hecho religioso, en base a la constatación sistemática del mismo entendido como FENOMENO SOCIAL, bajo el criterio específico de la ciencia antropológica.

Esto nos da pie muy oportuno, para pensar (desde nuestro reducto) que en nuestras culturas aborígenes, no sólo se da un "pensamiento" no científico, sino que la valoración racional de dicho pensamiento no puede darse sino desde nuestro ángulo científico.

Esto explica la apreciación occidentalista (muy nuestra por cierto en muchos casos), que nos lleva a considerar con indulgencia (si no con desprecio y casi horror) la manera infantil, por decir lo me- nos, de interpretar la realidad, que es propia de nuestros bárbaros.

Tal prejuicio nos ha conducido a teñir de tintes casi exclusivamente negativos y prohibidos a conceptos como mito, magia, tab1í, etc. Recordemos, muy de paso nada más, quienes hemos estudiado teología, el minucioso empeño que se ponía en despejar cualquier parecido entre sacramentum o sacramentale y ritmo mágico.

Los misioneros de la Compañía de Jesús, varones de recia formación tomística y aristotélica, desempeñaron papel muy destacado en la aculturización (o inculturización) del continente americano. De aquí que venga muy al caso lo siguientes:

Lucien Lévy-Bruhl, en su libro La mentalité primative afirma:

Entre las diferencias, que separan la mentalidad de las sociedades inferiores de la nuestra, hay una que ha suscitado vivamente la atención de aquellos, que las han observado en forma directa y primordial..... 
Han constatado entre los primitivos una aversión decidida al razonamiento, a aquello que los lógicos llaman las operaciones discursivas del pensamiento por ejemplo los padres Jesuitas, que fueron los primeros en observar a los indios del este de América del Norte no pueden menos de hacer la reflexión siguiente: "no queda sino concluir que los iroqueses son incapaces de razonar, a diferencia ele los chinos u otros pueblos cultos. A quienes se puede demostrar la fe y la verdad de un Dios..... Los iroqueses no se mueven por razones..... los motivos de credibilidad, de los que normalmente hace uso la teología, para convencer aún a los espíritus más fuertes, aquíno son ni siquiera escuchados y las más grandes verdades son calificadas de mentiras....

Las verdades evangélicas no les son asequibles, si están apoyadas solamente por la razón y el sentido común. Puesto que carecen de letras y de cultura (politesse), es menester acudir a argumentos gruesos y palpables, para hacer impresión en sus espiritus. Aunque se encuentran entre ellos mentes capaces de la ciencia como europeos, sin embargo su educación y la necesidad de buscar la vida los ha reducido a tal situación, que su razonamiento no va más allá de lo que se refiere al bienestar corporal, al éxito en la cacería, en la pesca, en el comercio y en la guerra. $Y$ todas estas cosas son como otros tantos principios, de los que sacan tocias sus conclusiones, no solamente para el albergue, las ocupaciones y modo de obrar, sino aun para sus supersticiones y sus divinidades (Relaciones de los Jesuitas, Ed. Thwaits: t. LVII, pp. 126; 1672-3)

Lo leído es cifra de toda una mentalidad ampliamente extendida. Ni las culturas orientales avanzadas se libran de este prejuicio.

Antes de pasar a otro capítulo, dejo claro que el calificativo de primitivo lo mismo que el de no lógico se sujeta a una forma de hablar y pensar convencional hoy en día ampliamente rechazada por muchos antropólogos. No olvidemos el respetabilísimo y documentadísimo parecer de Claude Lévi-Strauss sobre la lógica de los primitivos y sobre que no existen culturas superiores o inferiores. 


\section{Aclaración de algunos términos}

Si bien mantengo lo dicho acerca de la tónica de mi trabajo, juzgo indispensable la precisión de los vocablos, que conforman el título general: pensamiento, lógico, mítico.

Pensamiento:

Como sus parientes (LOGOS, ratio, idea, etc.), posee diversidad de contenidos. Acojo una descripción de Descartes, si bien no me atengo a sus connotaciones racionalistas y conscientistas: (1641) dice:

En la segunda de sus Meditationes de prima philosophia

Qu'est-ce qu'une chose qui pense? C'est une chose qui doute, qui entend, qui conceit, qui affirme, qui veut, qui ne veut pas, qui imagine aussi et qui sent.

Descartes adjunta a la múltiple actividad de pensar la nota indefectible de conciencia: dicen en los "Principes de la philosophie".

Cogitationis nomine intelligo illa omnia quae nobis conscii in nobus sun, quatemus eorum in nobis conscientia est.

Dejemos de lado la cuestión de la conciencia como requisito indispensable o no del pensamiento o de la idea. Recordemos nada más que más de un filósofo vitalista reniega de Descartes.

Recojamos lo muy valioso de la implicación de la totalidad del ser (humano) de la descripción cartesiana. Así hagamos válida la generalización de Andre Lalande "Au sens le plus large, il (el concepto de "pensée) enveloppe tous les phénomenes de l'esprit" (6). Y bajo ese signo aclaremos:

1. Es pensamiento toda actividad del ser humano en cuanto tal, por ende referida de alguna manera a la conciencia.

2. El pensamiento no es una actividad puramente individual, sino también colectiva.

3. Con estos elementos, entendamos por pensamiento la toma de conciencia de la realidad por parte de un grupo humano, con su modo peculiar de interpretarla y expresarla. La cual hallándose 
vinculada a un espacio y a un tiempo (a una historia) constituye en fin de cuenta la CULTURA.

Lógico:

Así mismo, dejando de lado las más variadas discusiones, aceptémoslo como la forma de pensar, el método, que enfoca la realidad, la desentraña y organiza bajo los términos siguientes:

1. El juicio, que consiste en la comparación de dos ideas (un sujeto y un predicado) teniendo como eje el verbo SER, el cual se rige por las leyes del SER (sustantivo).

2. El raciocinio, que es la comparación concatenada de juicios, así mismo bajo la égida del SER (verbo y sustantivo) y cuyo mecanismo elemental es el silogismo, del cual dimana la conclusión.

3. La deducción y la inducción, como formas orgánicas, que justifican la veracidad de las conclusiones y que son las vías legítimas, para de lo general descender racionalmente a lo particular (a lo existente o capaz de existencia), o del caso existente ascender a la ley universalmente válida.

Digo que la lógica, entendida así, es la tónica predominante del enfrentamiento filosófico y cultural del grecooccidental con el KOSMOS (al cual, por cierto, nos vamos a restringir). Si es verdad, como más adelante veremos, que la gran pregunta del pensamiento helénico es el TI TO ON, es cierto también que ella se mueve bajo la disciplina de la lógica.

\section{Mítico:}

De él trataremos en capítulo especial. Si bien el "primitivo", por el hecho de ser hombre, no desconoce el juicio, sin embargo, en su aproximación a la realidad, no se somete al rigor metodológico fincado en el verbo y en el sustantivo SER. Su cercanía al Kosmos y su conocerlo y moverse en él, se rige más bien por percepciones globales, que se expresan mejor dentro del simbolismo, el misterio, la creencia como propia afirmación del presente en base a lo que fue. 


\section{La apertura al Kosmos de los Griegos y Latinos.}

Todos los entendidos dan por innegable que todos los pueblos europeos, incluidos los griegos y latinos, pasaron de una etapa "inmadura" (mítica) a la mayoría de edad (lógica).

Las fronteras son vagas, los años son muchos, en la transición. Por mucho tiempo (en algo, para siempre) coexisten las dos modalidades de cultura. En la filosofía existe dicha penumbra. Como dato externo observemos que el científico Hermann Diels, en su magnífica edición de los filósofos presocráticos, tiene que remontarse a figuras que, ellas mismas (por no decir nada de su pensamiento) son parte de lo mítico, tal el caso de Orfeo y Museo.

Si bien no es argumento convincente que un pensamiento, por estar expresado en verso, no sea filosófico; sin embargo, es interesante recordar que Parménides, el padre de la lógica del TO ON, escribió su rígida disquisición en hexámetros (el mismo metro de la Ilíada y de la Odisea) y nos abrió la puerta al HODOS TES ALETHEIAS desde la mansión de la Noche bajo la guía de diosas.

Pese a ello, y más en lo que atañe al filosofar, hay una diferencia claramente captada por los sabios griegos entre lo que es un pensar (un argüir) mítico y un pensar (un dar razones) filosófico. Hay al respecto un texto de Aristóteles muy decidor: en el capítulo tercero del libro tercero de la Metafísica, partiendo de la afirmación probada de que "manifestum sit quod primarum causarum oportet scientiam accipere....." ":

Echa una mirada a opiniones pasadas: "Plurimi igitur eorum, qui primi philosophati sunt, solas illas existimarunt omnium esse principia, quae in materiae specie sunt. Ex quo enim omnia entia sunt, et ex qua primo fiunt". $Y$ continúa: "Pluralitatem tamen et speciem hurus principii, non eandem omnes dicunt; sed Thales quidem, huiusmodi philosophi principeps, autem ait esse. Fortassis hanc habuit apinionem, quia nutrimentum omnium humidum esse vidabat, et ipsum quoque calidum ex eo factum eoque vivere: ex qua autem aliquid fir, id est principium omnium. 
Propter hoc igitur hane habuit opinionem, et quoniam cunctorum semina naturam humidam sortita sunt; aqua vero naturae principium humidi est.

Hay quienes opillan que aquellos señores viejísimos y enormemente alejados de nosotros se lanzaron a estas teorías por motivos teológicos. Ya que cantaron a Océano y Testis como los padres de toda generación. Además el juramento de los dioses es el agua, la cual es llamada Estigia por los poetas. Lo más antiguo es aquello que es lo más honorable y no hay nada más que el juramento".

Sobre el mismo tema, y dentro de un mismo medio cultural, resaltan dos formas de pensar, de argumentar. Y se ve patente la valoración, que de Aristóteles a esas dos argumentaciones:

\section{La primera (la de Thales) es FILOSOFÍA, La segunda es de TEÓLOGOS.}

Pero este nuevo enfrentamiento con el Kosmos tuvo su historia, su proceso, sus desconciertos dramáticos, que comprometieron al hombre total y no sólo a su mente raciocinante.

Frederick Copleston, en su volumen primero de la Historia de la Filosofía, nos habla de una nostalgia del griego culto por los tiempos mejores del pasado, de una melancolía radical ante la dureza de la vida humana, presente en el sufrir y en su culmen y suma la muerte:

Es grave error suponer que los griegos fueron felices y despreocupados hijos del sol, deseosos tan sólo de pasearse por los pórticos de las ciudades y de contemplar las magníficas obras de su arte o las proezas de sus atletas. Fueron también muy conscientes del aspecto sombrío de nuestra existencia sobre este planeta, pues en contraste con el sol y la alegría se percataban de la incertidumbre $e$ inseguridad de la vida humana, de la certeza de la muerte y de la oscuridad del futuro (7). 
Cabe ciertamente hablar de un tinte trágico del sentir griego. Y el toque trágico tiene honduras pavorosas y está claramente emparentado con el nuevo darse de la cultura. Ya en el siglo VIII antes de Cristo, Hesíodo ponía en boca de Theognis la siguiente frase: "Lo mejor para el hombre es no haber nacido y no haber conocido la luz del sol. Pero, si ha tenido la desgracia de nacer, la mejor solución es traspasar las puertas de la muerte lo más pronto posible". Y Sófocles en "Edipo en Colona" dice: "El no haber nacido supera a toda ponderación de cualquier bien".

La conclusión práctica más extrema de esta visión ennegrecida de la vida es el suicidio nihilista, que como tal es prerrogativa de grecooccidente.

El fondo de esta vivencia desconcertada descansa, en mucho en su nuevo planteamiento del Kosmos. El hombre griego (occidental) se siente distinto del mundo, peregrino en él, a la postre su adversario. En su estudio "COSMOS: Symbolique cosmobiologique" el antropólogo J. Goetz observa con mucho acierto que la tónica occidental frente al mundo, si bien tiene un ángulo poderoso de conciencia de superioridad ("Seréis como dioses"), está a la vez afectada de una angustiosa conciencia de soledad y abandono inermes, que puede llevar a una rebeldía y desesperación cósmicas. Y eso, cuya máxima expresión se halla en la literatura, llega a la paradoja de que los recursos mitológicos, los cuales (como veremos más adelante) eran la expresión de la armonía íntima entre el hombre y el Kosmos, se vuelven (como el caso del poeta Horacio) en el aviso y en voz de alerta de un divorcio sin remedio.

La conciencia (o subconciencia) colectiva de un mal original estrechamente vinculada con el aparecer del hombre (la cual se da ya en los primitivos, como veremos), se agudiza en forma extrema y a la postre se identifica con el hecho mismo de la aparición del hombre en el mundo. Allá apunta lo que he citado de Hesíodo y de Sófocles. Como señala Copleston, no se borra ese pesimismo radical en Occidente, que va encontrando ecos de enorme patetismo a lo largo de siglos. Nos trae él a la memoria los versos, que Calderón de la Barca (tan caro al pesimista Schopenhauer), pone en boca de Segismundo, en la escena II de la Jornada Primera del Drama Filosófico en tres actos: La Vida es Sueño: 
.....Bastante causa ha tenido

vuestra justicia y rigor,

pues al delito mayor

del hombre es haber nacido.

\section{La Filosofía como solución greco-occidental al conflicto del hombre en el Kosmos}

Las vías de solución del problema han sido varias y en varias esferas (el sentido común, lo poético, LA RELIGION, etc.). El quedarse en él, por más honduras de pensamiento que hubiese producido, habría sido a la postre destructor.

Me concreto, de modo asertivo, en la vía filosófica. Dentro de ella afirmo como válido, en sentido general, el que la ruptura se mantiene básicamente. Esto no niega la existencia de movimientos, como el Renacentismo, el Romanticismo, que reconcilian parcialmente al hombre occidental con la NATURALEZA.

Fijemos la atención en dos modos de filosofar, ambos de suma importancia:

1. La "fuga" platónica: el calificativo es duro, pero cierto.

La suma más cabal de su pensamiento, en lo que se refiere a es- te punto, se halla en los libros VI y VII de la República. La estrechez del tiempo no nos permite sino apuntar ideas:

El mundo, en que movemur et sumus, es algo precario, una semirrealidad, la sombra de la gran realidad (el mundo de las ideas), a cuya contemplación (theoreia) y fruición está destinado el ser humano. $\mathrm{Su}$ ser en el mundo es transitorio y, en fin de cuentas, es un ser-enprisión. La patria está por encima del mundo sensible (mundo de meras apariencias, respecto del cual no cabe sino el mero conocimiento opinativo: he doxe). El peligro del hombre es vivir el engaño de este mundo como si fuese el suyo propio. Vencer tal engaño es empresa heroica y sujeta al riesgo aun de la muerte. Pero es menester arrostrarla. Para ello se impone una auténtica conversión de las cosas de este mundo, un darle las espaldas: SYN HOLE TE 
PSYCHE EK TOU GIGNOMENOU PERIAKTEON EINAI (República 518 B). Sólo entonces podrá encumbrarse con esfuerzo (por cierto) a través de los grados de la mente (incluido el discurso lógico), hasta encontrar- se; en el mundo de arriba, cara a cara con las ideas, en una contemplación (THEOREIA), que no tendrá fin.

Por ende, para Platón la fuga del mundo no sólo es el recurso para llegar al conocimiento auténtico, sino la 'opción trascendental del ser humano, su gran reto moral: despojarse, mediante una ascesis esforzada, de las cadenas del mundo engañoso, para alcanzar, más allá de él la suprema liberación.

Cuánto haya influido esta visión, por lo demás genial, en el múltiple obrar y decidir de Occidente (también de nuestro Occidente) no requiere ponderación.

2. El THA UMAZEIN y la inquisición lógica: Las reacciones del hombre solitario, que antes señalábamos, podrían llamarse en términos general como gestos o actitudes de inconformidad emocional. Esta fue tomando un matiz de inconformidad intelectual: ahí precisamente se hallaron los filósofos.

Hagamos mención primera, por su relevancia lógica, de Parménides, aunque posterior a los Kosmólogos. No olvidemos que la disuisición platónica, a la que acabamos de referirnos, supone como premisa, que trata de superar, la distinción irreductible, que traza Parménides entre el puro ser y el no ser.

Concibe Parménides dos vías (HODOI), es decir, dos mundos: el sensible, múltiple, mutable, sujeto al fenecer, y el del ser sin más, libre de aquellas vicisitudes. El primero es el mundo de la DOXA, es decir que las apariencias engañosas, el de la falsedad. En su engaño vive el hombre común, el hombre superficial (HOI DIKRANOI). El segundo es el auténtico, el de la verdad (TES ALLETHEIAS). A él se acoge el sabio, gracias a él se salva. Para ello se acoge a la ley del SER, que se halla en contradicción con las leyes de este mundo; dicha ley es precisamente la lógica mental, afirmada por él con un integrismo total:

He ahí, al vivo y sin transigencias, la inconformidad o la insatisfacción intelectual de los griegos frente a la naturaleza. 
Con el avance del pensamiento, la actitud se suaviza y enriquece. Se da una revaloración de lo sensible, pero siempre con la nota de distancia:

Aristóteles lo refiere como el THAUMAZEIN. La traducción castellana admirarse no da el alcance preciso; más exacta es la expresión inglesa I wonder; me pregunto con intriga. El preguntarse así supone no hallarse conforme con las incoherencias del dato inmediatamente presente. Tal inconformidad no se traduce en desconcierto o desinterés sino en la dinámica del inquirir. De ahí que el THAUMAZEIN deba explicarse como una inconformidad inquisitiva:

Así se entiende en plenitud la frase grandiosa de Aristóteles "dia gar to thaumazein hoi anthropio kai nyn kai to proton erxantophilosophein" (en virtud del thaumazein los hombres comenzaron a filosofar y siguen filosofando). Met. A2, 982 b $12 \mathrm{sg}$.:

El griego, el hombre occidental, busca desde la razón y sus leyes desentrañar la incógnita (la pregunta) del mundo. Tal búsqueda es radical en el sentido de ir hasta lo último (definición aristotélica de filosofía: TON PROTON ARCHON KAI AITION EPISTEME THEORETHIKE).

Tal intención de radicalidad tuvieron ya los primeros filósofos, al indagar el primer constitutivo del Kosmos. Luego la pregunta crece en amplitud y hondura, hasta convertirse en la más profunda que concebirse puede: TI TO ON.

Y esa inagotable tónica greco-occidental, de que nos habla Aristóteles: "kai de kai pelai te kai nyn kai aei zetoumenon kai aei aporoumenon ti to on" (así pues, entonces, ahora y siempre indagamos e incesantemente nos hallamos en la perplejidad de qué es lo qué es) (Met. 1. VII, 1, 1028 b2 sq.):

Allí el cimiento de una cultura grande, en constante aporía frente al mundo, que tiene que ser sujetado a la razón y a la lógica de un hombre, que sigue siendo peregrino en él. 


\section{La apertura al Kosmos del "primitivo".}

\section{El trauma de la experiencia inicial.}

Hay también en el primitivo, más que en el sentido temporal en el de esencia íntima, la conciencia inicial y latente del dolor de ser en este mundo. Expuesto a su inclemencia más que el urbano, vive como historia y como presente, el hecho inexorable del sufrir y del morir. También él vincula el hecho de la aparición del hombre sobre la tierra con la presencia oscura de un pecado. También para él se da la trilogía inicial de NACIMIENTO-PECADO-MUERTE. La muerte es la pena que debe pagarse por aquel pecado ancestral, que tiene algo que ver con el hacer. Los mitos de origen abundan en ello. Citemos a modo de empleo de Popol Vuh:

Por no haber comprendido al Corazón del cielo, por su maldad fueron los hombres hechos de madera condenados a morir. Y vino la inundación en forma de lluvia espesa, como el trementina, bajando del cielo..... Fueron pues pulverizados, despedazados y castigados. Por no haber comprendido la presencia de sus progenitores, del Corazón del Cielo; se oscureció la superficie de la tierra y cayó una lluvia negra como las tinieblas, lloviendo de día y de noche..... Mucho nos hiciste sufrir les dijeron los perrillos y las gallinas..... Así pues fue destruida la gente, la criatura humana, por su maldad..... (Edición de Emilio Gómez pg. 19).

Esta subconciencia permanece en ellos como un rescoldo y se renueva con patetismo en las situaciones límites (conferencia del misionero austríaco en el Teologado de Innsbruck).

\section{La vivencia de una solidaridad radical con el Kosmos.}

Pero esta quiebra inicial es afrontada y resuelta por el primitivo a su modo: A diferencia del greco-occidental, para el primitivo el MUNDO (inhóspito y todo) sigue siendo su morada. Lo que en él se da (astros, tierra, plantas, animales) son a la postre sus compañeros de suerte. Ante el desconcierto inicial frente principalmente a la gran Naturaleza (tierra, sol y luna), que se presentan imponentes y superiores, sobre todo en lo que se refiere al subsistir; llega el primitivo a "intuir" que en el fondo existe una comunidad de SER y de DESTINO, y en tal sentido, una afinidad radical, que puede concretarse en las siguientes características: 
1. Unidad en el hecho de la vida. El primitivo es panvitalista. La vida es un unum existens y transcendes de enorme importancia, para captar la Weltanschaung del primitivo. Escuchemos lo que dice Mircea Eliade en su libro "Tratado de Historia de las Religiones":

La vida, como realidad única, es común a todas las cosas, hombres, animales, plantas y, en general el cosmos. Gracias a ella nada hay ajeno al hombre primitivo y él no es ajeno a nada. Todo lo que sucede en un punto del Kosmos, sucede a la vida y por lo tanto afecta a todos. Cualquier crecimiento de la vida es crecimiento de tocios. En consecuencia inmediata:

2. Comunidad de sufrir y morir: sufre y muere esa vida única. En nueva consecuencia:

3. Comunidad de esperanza, sobre todo en el sentido de perpetuo rehacerse de la vida, es decir de un perpetuo resucitar para todos.

4. El saldo final del primitivo es optimista y se expresa de manera firme en: Coherencia de lo incoherente: sin hacerse problema con la lógica del verbo SER, sabe él que la vida hermana lajusticia con la injusticia, la paz con la guerra, etc. Más aún, la punga, como hecho dinámico y conmovedor, es fuente de bien: POLEMOS PATER PANTON. A la final, la misma vida surge, rehaciéndose, de la muerte, en un constante intercambio, como sucede con el trigo y los frutos de la tierra, con la tierra misma o la luna o el sol. De ahí esa visión de VITA EX MORTE, que expresa tan maravillosamente el filósofo mítico Heráclito:

Inmortales, mortales, mortales, inmortales. Vivimos la muerte de otros ( $f g$. 62).

5. Temporal velamiento de esta realidad unánime: por aquel mal (pecado) se crea una distancia entre el hombre y la naturaleza, y aun entre elementos de la misma. Hubo un "aquel tiempo" en que todo era claro (en que los animales hablaban con los hombres). Pero, no obstante la oscuridad, la realidad profunda sigue vigente, aunque oculta. Ella no puede, en este tiempo, conocerse sino por un lenguaje aproximado (símbolos). Aquel tiempo retornará a su plenitud (concepto distinto del tiempo occidental), y la realidad profunda volverá a ser diáfana. Entonces se mitigarán los males. 
6. Y todo esto en virtud de un SER superior (la vida en plenitud) o más bienloquealimentalavida), quedarazóndeserlomismoal sol que al hombre: del cual participamos todos.

7. De todo esto se sigue que el primitivo esté conforme con el mundo, aún con el mal del mundo, que le afecta (su aceptación de la muerte, su no tendencia al suicidio, etc.).

8. Por ello no se enfrenta intelectualmente con el mundo: poco sentido tiene para él querer explicárselo en sentido causal: preguntarse ¿por qué? El primitivo más bien CONTEMPLA el mundo: esa es su admiración y de ahí surge su tendencia a adorarlo. Aquí está quizás la raíz de su poco interés por lo CIENTIFICO, por lo TECNICO. Lo que aparta del mundo, de la tierra sensible y húmeda, lo aleja de su hogar, de lo que es su pertenencia.

9. Más bien, como acertadamente observa J. Goetz, su curiosidad, surgida de una necesidad de afirmarse en las raíces remotas, se torna en la pregunta COMO COMENZAMOS. Y la respuesta es ilógica para nuestra lógica.

\section{EL MITO: suprema expresión de este ser en el Kosmos.}

El Mito no es:

a) Quimera.

b) Pura alegoría.

c) Pura forma pedagógica.

d) Historia unívoca: en sentido occidental racionalista.

Sino:

El MYTHOS, en su genuidad primordial, es la expresión simbólica de todo lo que hemos descrito anteriormente. Por lo tanto el símbolo, que desarrolla el mito, tiene en sí un contenido y una verdad; tiene una presencia y una eficacia en sí mismo. 
Lo importante en el personaje mitológico (en el hecho mitológico (en el HEROE) es su condición de ARQUETIPO: se trata de algo no totalmente distinto del hombre y del Cosmos o situado por encima de ellos (como sucede con los dioses del Olimpo greco-roma no), sino íntimamente ligado con ellos, en lo cual el hombre se reconoce a sí mismo y reconoce al Cosmos, algo (como dije) de lo cual participan el hombre y el Kosmos.

Dr. Hernán Malo González.

\section{NOTAS}

(l) Arturo Andrés Roig, "Esquemas para una historia de la filosofía ecuatoriana", Quito. Ed. de la Universidad Católica. 1977. Ver, a más del prólogo, todo el cap. primero.

(2) Martin Heidegger, "Was ist das die Philosophie", Tiibillge11, 1956, pp. 13 y 14.

(3) Hegel, "Geschichte der Philosophie", tomo primero, Frankfurt, Ed. Suhrhamp, 1971, capitulo sobre "Abscheidung des Orients und seiner Philosophie ", pp. I18-12I.

(4) Jacinto Jijón y Caamaño, "La religión del Imperio de los Incas", Quito, Tip. y Encuad. Salesianas, J 919, ver prólog.

(5) Lucien Léuy-Bruhl, "La menlalité primitive", Paris, 1940, pp. 1 yss.

(6) Véase "Pensée" en "Vocabulaire de la Philosophie" de Andre Lalande.

() Federich Copleston, "Historia de la Filosofía ", Barcelona, 1974, Vol. I, p. 33. 